\title{
Bioequivalence and Pharmacokinetic Evaluation of Two Formulations of Armodafinil 250 mg Tablets in Healthy Indian Adult Male Subjects
}

Menon $\mathbf{S}^{1 *}$, Kandari $\mathbf{K}^{1}$, Mhatre $\mathbf{M}^{1}$ and Nair $\mathbf{S}^{1}$

Institute for Advanced Training and Research in Interdisciplinary Sciences (Therapeutic Drug Monitoring Laboratory), Mumbai- 400022, India

\begin{abstract}
Armodafinil the R-enantiomer of modafinil is involved in managing sleep disorder consisting of excessive sleepiness associated with obstructive sleep apnea, narcolepsy and shift work disorder. The aim of the study was to establish bioequivalence and tolerability between two formulations of armodafinil. This was an oral comparative bioequivalence study in healthy Indian subjects. The study design was a crossover, randomized, open label singledose, two-treatment, two-period, two-sequence type. Under fasting condition all the subjects $(26+4$ stand-by) received test and reference formulation in a staggered manner by a randomization code list in both the period with a washout period of seven days between the treatment periods. Twenty blood samples were drawn from each subject over 96 hours in each period. Liquid- liquid extraction method was validated using high performance liquid chromatography. The pharmacokinetic parameter $\mathrm{C}_{\max }(\mathrm{ng} / \mathrm{ml}), \mathrm{T}_{\max }(\mathrm{hr}), \mathrm{AUC}_{(0-\mathrm{t})}\left(\mathrm{ng} / \mathrm{ml}{ }^{*} \mathrm{hr}\right)$, and $A \cup \mathrm{C}_{(0-\infty)}\left(\mathrm{ng} / \mathrm{ml} \mathrm{k}^{*} \mathrm{hr}\right)$ $\mathrm{T}_{1 / 2}(\mathrm{hr})$ and $\mathrm{K}_{\mathrm{el}}\left(\mathrm{hr}^{-1}\right)$ were determined for armodafinil in reference and test formulations. ANOVA showed no significant variation in these parameters. Relative bioavailability of $97.78 \%$ was calculated for armodafinil. The $90 \%$ confidence interval of log transformed data comparing test formulation versus reference formulations for $\mathrm{C}_{\max }, \mathrm{AUC}_{(0-\mathrm{t})}$ and $\mathrm{AUC}_{(0-\infty)}$ are within the acceptance range of bioequivalence ( $80 \%$ to $125 \%)$.
\end{abstract}

Based on the pharmacokinetics parameters of armodafinil (test and reference), it is concluded that single dose of single dose of armodafinil tablet containing $250 \mathrm{mg}$ armodafinil manufactured by Emcure Pharmaceuticals, India. is bioequivalent to single dose of Nuvigil tablet containing $250 \mathrm{mg}$ armodafinil manufactured by Cephalon, Inc., USA.

Keywords: Armodafinil; Pharmacokinetics; Bioequivalence

\section{Introduction}

Modafinil is wakefulness-promoting medication in a number of species [1-7] and is useful for the treatment of excessive sleepiness associated with narcolepsy, obstructive sleep apnea/hypopnea syndrome, and shift work sleep disorder [8-10]. Compared to other stimulants, it has fewer side effects and has low potential risk of dependence. Modafinil is a chiral compound with both R-and S-enantiomer pharmacologically active. However, it has been reported that R-enantiomer has a longer half life and hence long lasting effect as compared to the S-enantiomer. Armodafinil is the R-enantiomer of racemic modafinil, 2-[(diphenylmethyl) sulfinyl]acetamide. Like modafinil, studies on Wistar Kyoto rat and Sprague Dawley rat have proven armodafinil to be wake promoting [11-15]. Research conducted by Elaine et al. has demonstrated that armodofinil activated many brain regions similar to that modafinil. Furthermore, it has been reported that armodafinil activates the $\mathrm{c}$-fos expression in many brain regions that is associated with the waking phase of the sleep/wake cycle $[16,17]$.

Studies were also performed to establish the pharmacokinetic profile of armodafinil in rat. On a comparative basis, $200 \mathrm{mg}$ armodafinil showed higher plasma concentrations, improved wakefulness, and longer sustained attention than $200 \mathrm{mg}$ modafinil in a study of acutely sleep-deprived healthy human volunteers [18-20]. Armodafinil and modafinil are nonamphetamine, wakefulness-promoting medications approved by the US Food and Drug Administration (FDA) for treatment of excessive sleepiness associated with treated obstructive sleep apnea (OSA), shift work disorder, and narcolepsy [21,22]. Armodafinil is eliminated approximately three times more slowly than the $S$ - isomer of racemic modafinil [23]. There are scientific research articles demonstrating the efficacy of armodafinil for treating excessive sleepiness [23].

Armodafinil $250 \mathrm{mg}$ tablets were prepared for the generic switching over the other branded generic drug. For prescription, the tablets formulation of Emcure Pharmaceuticals Ltd., India should show bioequivalence to the innovator tablet formulation of the same drug. Therefore a study in Indian healthy male subjects was conducted to establish bioequivalence and to obtain pharmacokinetics profile of both the formulations of armodafinil.

\section{Material and Method}

The test product was armodafinil tablet containing armodafinil $250 \mathrm{mg}$ manufactured by Emcure Pharmaceuticals Ltd., India. The reference product was Nuvigil tablet containing armodafinil $250 \mathrm{mg}$ manufactured by Cephalon, Inc. USA.

The study was conducted at Therapeutic Drug Monitoring Laboratory (TDML), Sion, India. The study participants were screened as per the DCGI (Drug Controlled General of India) approved protocol after obtaining signed informed consent form (ICF) from each of the study participants. The screen passed subjects were enrolled and screen failed subjects were excluded. All subjects agreed to abide by the diet and fluid restrictions and also to undergo all procedures as required by the study. Study abstained from xanthine containing foods, tobacco and alcohol for a time span of 48 hours prior to first study

*Corresponding author: Menon S, Institute for Advanced Training and Research in Interdisciplinary Sciences (Therapeutic Drug Monitoring Laboratory), 194, Scheme no. 6, Road no. 15, Sion-Koliwada, Sion, Mumbai- 400022, India, E-mail spmtdmlab@gmail.com

Received February 02, 2013; Accepted March 08, 2013; Published March 14 2013

Citation: Menon S, Kandari K, Mhatre M, Nair S (2013) Bioequivalence and Pharmacokinetic Evaluation of Two Formulations of Armodafinil $250 \mathrm{mg}$ Tablets in Healthy Indian Adult Male Subjects. J Bioequiv Availab 5: 095-098. doi:10.4172/ jbb.1000141

Copyright: ( 2013 Menon S, et al. This is an open-access article distributed under the terms of the Creative Commons Attribution License, which permits unrestricted use, distribution, and reproduction in any medium, provided the original author and source are credited. 
drug administration until the last sample is collected with follow up as required by the study protocol. The protocol, ICF and screening form were approved by the institutional ethics review committee before conducting the study. The study was conducted in accordance with ICH guidelines on GCP, ICMR guidelines on Biomedical Research, CDSCO Bioavailability Bioequivalence guidelines, the provisions of Declaration of Helsinki (Seoul, October 2008).

The study population consisted of $26+4$ (stand-by) Indian healthy male subjects aged between 18 to 45 years with a mean of 26.9 years, mean weight of $61.6 \mathrm{~kg}$ and mean height of $165.6 \mathrm{~cm}$. The study was randomized, open-label, single-centre, two-treatment, two-period, two-sequence, single-dose, crossover, in vivo oral bioequivalence study with wash-out period of seven days between each treatment.

The dosing was done after an overnight fasting of at least 10 hours for each volunteer. The dosing was done orally in sitting posture. During each study period, each subject was administered with one 250 mg tablet of armodafinil [test product (A) or reference product (B)] with $240 \mathrm{~mL}$ of water at ambient temperature as per the randomization generated at TDML which was followed by mouth check to assess the compliance to dosing. No water was permitted 1 hour before and 2 hours after dosing.

Pre labelled centrifuge tubes with $\mathrm{K}_{2}$ EDTA as an anticoagulant was used for blood sample collection. The blood samples were collected by introducing an indwelling venous cannula in the subjects left/ right forearm vein. Post-dose sampling time points after formulation administration were $0.50,1.00,1.25,1.50,1.75,2.00,2.25,2.50,3.00$, $4.00,6.00,8.00,10.00,12.00,16.00,24.00,48.00,72.00$ and 96.00 hours. A total of 20 blood samples including pre dose sample, per period for armodafinil analysis were obtained. Accurate note of actual collection time was made for each blood sample. Blood samples between 0.50 to 24.00 hours post dose were collected from the cannula by discarding the first $0.5 \mathrm{ml}$ of blood. While the remaining samples after 24.00 hours are taken by vein puncture. Plasma sample was obtained by carrying out separation using refrigerated centrifuge at $4000 \mathrm{rpm}, 0-4^{\circ} \mathrm{C}$ for 10 minutes followed by direct transfer into two $5 \mathrm{~mL}$ polypropylene tube and stored at $-20^{\circ} \mathrm{C}$ until analysis.

\section{Method of Analysis}

Plasma concentration of armodafinil was quantified using High Performance Liquid Chromatography (HPLC) system that was validated before the study. Dichloromethane liquid-liquid extraction procedure was used to extract the armodafinil from the plasma. The residue was reconstituted in $200 \mu \mathrm{L}$ of mobile phase and $25 \mu \mathrm{L}$ was injected onto the chromatographic system. Sensitivity, specificity, ruggedness, calibration range curve, precision, accuracy, recovery and stability were the parameters performed for validation. The six point calibration curve demonstrated a good linear range for armodafinil in the concentration range $100.0 \mathrm{ng} / \mathrm{mL}$ to $8000.0 \mathrm{ng} / \mathrm{mL}$. Furthermore, a linear regression coefficient greater than 0.9823 for analyzed calibration curves was obtained. The detection limit and quantification limit for armodafinil was $40.0 \mathrm{ng} / \mathrm{mL}$ and $50.0 \mathrm{ng} / \mathrm{mL}$ respectively. The $\%$ nominal for interday precision and accuracy for the quality control samples $(300 \mathrm{ng} / \mathrm{mL}$, $4000 \mathrm{ng} / \mathrm{mL}$ and $7000 \mathrm{ng} / \mathrm{mL}$ ) varied from $103.10 \%$ to $103.70 \%$; while the $\%$ nominal for intra-day precision and accuracy were between $94.66 \%$ and $103.97 \%$. The $\%$ CV for inter-day precision and accuracy for the quality control samples were between $3.39 \%$ and $7.22 \%$; while $\% \mathrm{CV}$ for intra-day precision and accuracy varied from $1.60 \%$ to $3.23 \%$. The $\%$ recovery for the analyzed quality control samples was in the range $73.79 \%$ to $90.12 \%$. Plasma stability of Armodafinil was evaluated as freeze-thaw cycle stability, bench top (room temperature) stability, auto-sampler stability, short term stability and long term stability. The acceptance criteria for the parameters studied during validation was as per FDA validation guidelines [24-26]. The \%CV and \%difference for the short term stock solution stability (6hrs) was $1.14 \%$ and $-0.71 \%$; whereas for long term stock solution stability, it was $1.15 \%$ and $1.19 \%$. The $\% \mathrm{CV}$ and \%difference for freeze-thaw cycle stability varied from $1.57 \%$ to $7.35 \%$ and $-4.24 \%$ to $0.28 \%$ respectively. Similarly, the $\% \mathrm{CV}$ and \%difference for long term stability in matrix (evaluated for a period of 14 days) ranged from $1.15 \%$ to $3.96 \%$ and $-12.84 \%$ to $14.69 \%$. The

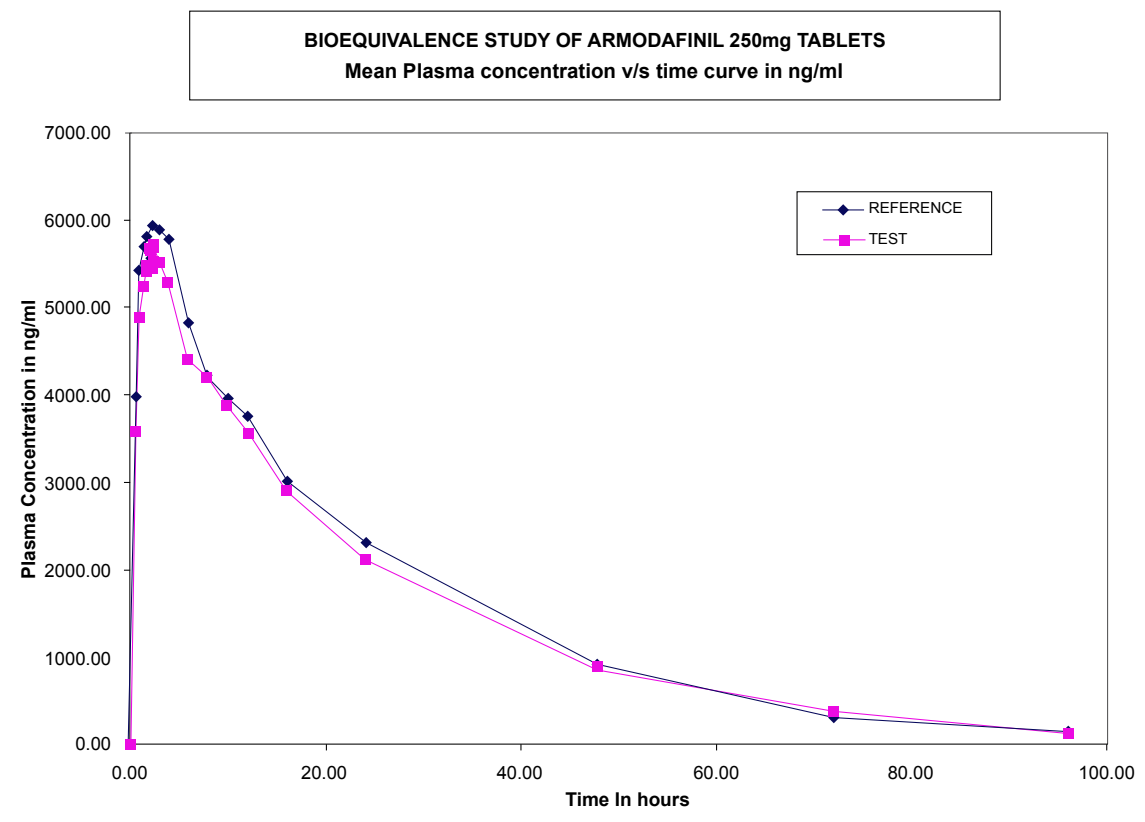

Figure 1: Mean plasma concentration $(\mathrm{ng} / \mathrm{mL}$ ) versus time curve (hour) of armodafinil $250 \mathrm{mg}$ tablets (test and reference). 
developed liquid- liquid extraction procedure was found to be simple, robust and provide high recovery rate, resulting in a fast and easilyhandled analysis.

\section{Pharmacokinetics and statistical analysis}

The Pharmacokinetic parameters are derived by using SAS software (Version 9.1-Revision 9.1.3 SAS Institute, USA) and Microsoft Office 2000. The following pharmacokinetic parameters $C_{\max }, T_{\max }, A U C_{(0-t)}$ and $\mathrm{AUC}_{(0-\infty)}$ were reported for both the investigational products. The $\log$ transformed pharmacokinetic parameters $\left(\mathrm{C}_{\max }, \mathrm{AUC}_{(0-1)}, \mathrm{AUC}_{(0-\infty)}\right)$ were subjected to statistical Analysis of Variance (ANOVA) [27] and two-one sided ' $\mathrm{t}$ ' test for determining the bioequivalence between the two investigational products. Also a ratio analysis of untransformed and log transformed pharmacokinetic parameters $\left(C_{\max }, A U C_{(0-t)}\right.$, $\left.\mathrm{AUC}_{(0-\infty)}\right)$ were carried out. Along with $\mathrm{T}_{\max }$ the elimination half-life $\left(\mathrm{T}_{1 / 2}\right)$ and terminal phase elimination rate constant $\left(\mathrm{K}_{\mathrm{el}}\right)$ were also determined. For a product to be bioequivalent in compliance with current FDA guidelines, the $90 \%$ confidence interval for $\mathrm{C}_{\max }, \mathrm{AUC}_{(0-\mathrm{t})}$ and $\mathrm{AUC}_{(0-\infty)}$ should fall within the range of $80 \%-125 \%$ [28-30].

\section{Results and Discussion}

All twenty six and four stand-by volunteers completed both the periods of the study and all were discharged in good health. There were no dropouts and/or withdrawal in the study. No serious adverse events were reported and there were no clinically significant changes in vital signs, clinical laboratory variables, ECG, X-ray and general physical examination. The validated method used for quantification of armodafinil in human plasma showed good specificity, sensitivity, linearity, precision and accuracy. All the stabilities performed were under acceptance criteria as per standard guidelines of US FDA. Accuracy of calibration curve and quality control samples were within the acceptance limit of $85 \%$ to $115 \%$.

The mean plasma concentration versus time curves of armodafinil (test and reference) to the twenty six subjects is given in figure 1 . The calculated pharmacokinetics parameters of armodafinil are summarized in table 1 . In both the test and reference formulations $\mathrm{C}_{\max }, \mathrm{AUC}_{(0-\mathrm{t})}, \mathrm{AUC}_{(0-\infty)}$ and $\mathrm{C}_{\max } / \mathrm{AUC}_{(0-\infty)}$ values were comparable. The test/reference of geometric mean of $\mathrm{C}_{\max }, \mathrm{AUC}_{(0-\mathrm{t})}$ and $\mathrm{AUC}_{(0-\infty)}$ for armodafinil in both formulation were $95.77 \%, 97.78 \%$ and $97.96 \%$ respectively (Table 2). These values were within acceptance limit of 80-120\%. ANOVA was applied with period, sequence and treatments as variables for armodafinil, no significant variation were observed. When ANOVA was applied with subject as variables for armodafinil, significant variation was observed for $\mathrm{C}_{\max }, \ln \mathrm{C}_{\max }, \mathrm{AUC}_{(0-\mathrm{t})}, \ln \mathrm{AUC}_{(0-\mathrm{t})}$, $\mathrm{AUC}_{(0-\infty)}, \ln \mathrm{AUC}_{(0-\infty)}, \mathrm{C}_{\max } / \mathrm{AUC}_{(0-\infty)}$ and $\left.\ln \mathrm{C}_{\max } / \mathrm{AUC}_{(0-\infty)}\right)$. When AUC $_{(0-t)}^{(0-\infty)}$ of both formulations for untransformed data are compared, test formulation showed a bioavailability of $95.76 \%$ as compared with the reference formulation and for geometric mean data test formulation showed a bioavailability of $97.78 \%$ as compared with the reference formulation, which is within the acceptance limit of $80 \%$ to $120 \%$. The $90 \%$ confidence interval for the ratio of In-transformed $\mathrm{C}_{\mathrm{max}}, \mathrm{AUC}$ and $\mathrm{AUC}_{(0-\infty)}$ were $88.82 \%$ to $103.25 \%, 92.00 \%$ to $103.93 \%$ and $91.94 \%$ to $104.37 \%$ respectively meeting armodafinil bioequivalence criteria (Table 3). Furthermore the mean $\mathrm{T}_{\max }$ and $\mathrm{T}_{1 / 2}$ obtained from the test drug is comparable with reference drug.

\section{Conclusion}

In this study, both the formulations were well tolerated. The

\begin{tabular}{|c|c|c|c|c|c|c|c|c|}
\hline \multirow{2}{*}{$\begin{array}{l}\text { Pharmacokinetic } \\
\text { Parameters of } \\
\text { Armodafinil }\end{array}$} & \multirow[b]{2}{*}{ Mean } & \multicolumn{2}{|c|}{ REFERENCE } & \multirow[b]{2}{*}{$\% \mathrm{CV}$} & \multirow[b]{2}{*}{ Mean } & \multirow{2}{*}{$\begin{array}{l}\text { TEST } \\
\text { S.D. }\end{array}$} & \multirow[b]{2}{*}{ S.E. } & \multirow[b]{2}{*}{$\% \mathrm{CV}$} \\
\hline & & S.D. & S.E. & & & & & \\
\hline $\mathrm{C}_{\max }(\mathrm{ng} / \mathrm{ml})$ & 6959.753 & 2559.8374 & 502.0254 & 36.78 & 6488.820 & 1004.7503 & 197.0477 & 15.48 \\
\hline $\mathrm{AUC}_{(0-\mathrm{t})}\left(\mathrm{ng} / \mathrm{ml} \mathbf{k}^{*} \mathrm{hr}.\right)$ & 143561.459 & 52789.8707 & 10352.9454 & 36.77 & 137472.353 & 32290.6130 & 6332.7102 & 23.49 \\
\hline $\mathrm{AUC}_{(0-\infty)}\left(\mathrm{ng} / \mathrm{ml} \mathrm{l}^{*} \mathrm{hr}.\right)$ & 147026.136 & 55298.4989 & 10844.9279 & 37.61 & 140994.394 & 33934.4906 & 6655.1012 & 24.07 \\
\hline$-1 C_{\max } / A U C_{(0-\infty)}(h r)$ & 0.0491 & 0.0106 & 0.0021 & 21.63 & 0.0480 & 0.0107 & 0.0021 & 22.27 \\
\hline $\mathrm{T}_{\max }(\mathrm{hr})$ & 1.875 & 0.9145 & 0.1793 & 48.77 & 2.288 & 1.2363 & 0.2425 & 54.02 \\
\hline$-1 \mathrm{~K}_{\mathrm{el}}(\mathrm{hr})$ & 0.048 & 0.0167 & 0.0033 & 34.38 & 0.044 & 0.0127 & 0.0025 & 28.90 \\
\hline $\mathbf{T}_{1 / 2}(\mathbf{h r})$ & 15.608 & 4.5168 & 0.8858 & 28.94 & 16.613 & 4.3864 & 0.8602 & 26.40 \\
\hline $\ln C_{\max }(\mathrm{ng} / \mathrm{ml})$ & 8.8095 & 0.2507 & 0.0492 & 2.85 & 8.7663 & 0.1552 & 0.0304 & 1.77 \\
\hline $\ln \mathrm{AUC}_{(0-\mathrm{t})}$ (ng/ml*hr.) & 11.8217 & 0.3250 & 0.0637 & 2.75 & 11.7992 & 0.2718 & 0.0533 & 2.30 \\
\hline $\ln A U C_{(0-\infty)}\left(n g / m l^{*} h r.\right)$ & 11.8441 & 0.3277 & 0.0643 & 2.77 & 11.8234 & 0.2756 & 0.0540 & 2.33 \\
\hline In $\left(C_{\max } / A U C_{(0-\infty)}\right)\left(h r^{-1}\right)$ & -3.0345 & 0.2001 & 0.0393 & -6.60 & -3.0572 & 0.2049 & 0.0402 & -6.70 \\
\hline
\end{tabular}

Table 1: Descriptive statistics of the pharmacokinetic parameters of armodafinil tablets and Nuvigil tablets administered to 26 healthy Indian adult male subjects.

\begin{tabular}{|c|c|c|c|}
\hline \multirow[t]{2}{*}{ Pharmacokinetic parameters } & \multicolumn{2}{|c|}{ Geometric Mean } & \multirow{2}{*}{$\begin{array}{c}\% \text { Ratio of } \\
\text { (ARMODAFINIL / NUVIGIL) }\end{array}$} \\
\hline & Reference & Test & \\
\hline $\operatorname{AUC}_{(0-t)}\left(\mathrm{ng} / \mathrm{ml} \mathbf{l}^{*} \mathrm{hr}.\right)$ & 136169.281 & 133151.327 & 97.78 \\
\hline AUC $_{(0-\infty)}\left(\mathrm{ng} / \mathrm{ml} \mathbf{l}^{*} \mathrm{hr}.\right)$ & 139257.705 & 136413.452 & 97.96 \\
\hline $\mathrm{C}_{\max }(\mathrm{ng} / \mathrm{ml})$ & 6697.852 & 6414.318 & 95.77 \\
\hline
\end{tabular}

Table 2: Geometric mean for armodafinil $250 \mathrm{mg}$ tablets (test and reference).

\begin{tabular}{|c|c|c|c|c|}
\hline \multirow[t]{2}{*}{ Data } & \multicolumn{2}{|c|}{$90 \%$ Confidence Interval } & \multicolumn{2}{|c|}{ Accepted $90 \%$ Confidence Interval } \\
\hline & Lower & Upper & Lower & Upper \\
\hline $\ln C_{\max }$ & 88.82 & 103.25 & 80.00 & 125.00 \\
\hline In $A U C_{(0-t)}$ & 92.00 & 103.93 & 80.00 & 125.00 \\
\hline In $A U C_{(0-\infty)}$ & 91.94 & 104.37 & 80.00 & 125.00 \\
\hline
\end{tabular}

Table 3: $90 \%$ Confidence interval for the pharmacokinetic parameters of armodafinil tablets versus Nuvigil tablets. 
Citation: Menon S, Kandari K, Mhatre M, Nair S (2013) Bioequivalence and Pharmacokinetic Evaluation of Two Formulations of Armodafinil 250 mg Tablets in Healthy Indian Adult Male Subjects. J Bioequiv Availab 5: 095-098. doi:10.4172/jbb.1000141

reported data were entirely within the bioequivalence acceptance range proposed by FDA of $80 \%$ to $125 \%$. From the data observed, it indicates that single dose of armodafinil tablet containing $250 \mathrm{mg}$ armodafinil manufactured by Emcure Pharmaceuticals Ltd., Pune, India will behave similarly as single dose of Nuvigil tablet containing $250 \mathrm{mg}$ armodafinil manufactured by Cephalon, Inc., USA and it can be considered to be a pharmaceutical alternative and exchangeable in clinical practice providing one more option.

\section{Acknowledgment}

This study was fully sponsored by Emcure Pharmaceuticals Ltd., Pune, India We are thankful to medical department of Emcure for their valuable technical inputs in preparing this manuscript.

\section{References}

1. Bastuji H, Jouvet M (1988) Successful treatment of idiopathic hypersomnia and narcolepsy with modafinil. Prog Neuropsychopharmacol Biol Psychiatry 12: 695-700.

2. Hermant JF, Rambert FA, Duteil J (1991) Awakening properties of modafinil: effect on nocturnal activity in monkeys (Macaca mulatta) after acute and repeated administration. Psychopharmacology (Berl) 103: 28-32.

3. Kopp C, Petit JM, Magistretti P, Borbely AA, Tobler I (2002) Comparison of the effects of modafinil and sleep deprivation on sleep and cortical EEG spectra in mice. Neuropharmacology 43: 110-118.

4. Lagarde D, Milhaud C (1990) Electroencephalographic effects of modafinil, an alpha-1-adrenergic psychostimulant, on the sleep of rhesus monkeys. Sleep 13: 441-448.

5. Lin JS, Roussel B, Akaoka H, Fort P, Debilly G, et al. (1992) Role of catecholamines in the modafinil and amphetamine induced wakefulness, a comparative pharmacological study in the cat. Brain Res 591: 319-326.

6. Shelton J, Nishino S, Vaught J, Dement WC, Mignot E (1995) Comparative effects of modafinil and amphetamine on daytime sleepiness and cataplexy of narcoleptic dogs. Sleep 18: 817-826.

7. Touret M, Sallanon-Moulin M, Jouvet M (1995) Awakening properties of modafinil without paradoxical sleep rebound: comparative study with amphetamine in the rat. Neurosci Lett 189: 43-46.

8. Czeisler CA, Walsh JK, Roth T, Hughes RJ, Wright KP, et al. (2005) Modafinil for excessive sleepiness associated with shift-work sleep disorder. N Engl J Med 353: 476-486.

9. Pack Al, Black JE, Schwartz JR, Matheson JK (2001) Modafinil as adjunct therapy for daytime sleepiness in obstructive sleep apnea. Am J Respir Crit Care Med 164: 1675-1681.

10.(1998) Randomized trial of modafinil for the treatment of pathological somnolence in narcolepsy. US Modafinil in Narcolepsy Multicenter Study Group. Ann Neurol 43: 88-97.

11. Harsh JR, Hayduk R, Rosenberg R, Wesnes KA, Walsh JK, et al. (2006) The efficacy and safety of armodafinil as treatment for adults with excessive sleepiness associated with narcolepsy. Curr Med Res Opin 22: 761-774.

12. Hirshkowitz M, Black JE, Wesnes K, Niebler G, Arora S, et al. (2007) Adjunct armodafinil improves wakefulness and memory in obstructive sleep apnea/hypopnea syndrome. Respir Med 101: 616-627.

13. Roth T, Czeisler CA, Walsh JK, Wesnes KA, Williams M, et al. (2005) Randomized, double-blind, placebo-controlled study of Armodafinil for the treatment of excessive sleepiness associated with chronic shift work sleep disorder. Sleep 30: s140.

14.14. Roth $T$, White $D$, Schmidt-Nowara W, Wesnes KA, Niebler G, et al. (2006) Effects of Armodafinil in the treatment of residual excessive sleepiness associated with obstructive sleep apnea/hypopnea syndrome: a 12-week, multicenter, doubleblind, randomized, placebocontrolled study in nCAP-adherent adults. Clin Ther 28: 689-706.

15.Wisor JP, Dement WC, Aimone L, Williams M, Bozyczko-Coyne D (2006) Armodafinil, the R-enantiomer of modafinil: wake-promoting effects and pharmacokinetic profile in the rat. Pharmacol Biochem Behav 85: 492-499.

16.Sagar SM, Sharp FR, Curran T (1988) Expression of c-fos protein in brain: metabolic mapping at the cellular level. Science 240: 13281331.

17.Cirelli C, Tononi G (2000) On the functional significance of c-fos induction during the sleep-waking cycle. Sleep 23: 453-469.

18.Scammell TE, Estabrooke IV, McCarthy MT, Chemelli RM, Yanagisawa $\mathrm{M}$, et al. (2000) Hypothalamic arousal regions are activated during modafinil-induced wakefulness. J Neurosci 20: 8620-8628.

19.Fiocchi EM, Lin YG, Aimone L, Gruner JA, Flood DG (2009) Armodafinil promotes wakefulness and activates Fos in rat brain Pharmacol Biochem Behav 92: 549-557.

20.Dinges DF, Arora S, Darwish M, Niebler GE (2006) Pharmacodynamic effects on alertness of single doses of armodafinil in healthy subjects during a nocturnal period of acute sleep loss. Curr Med Res Opin 22 159-167.

21.Provigil (modafinil) tablets [prescribing information]. Frazer, Pa: Cephalon, Inc; 2010.

22.Nuvigil (Armodafinil) tablets [prescribing information]. Frazer, Pa: Cephalon, Inc; 2010.

23.Darwish M, Kirby M, Hellriegel ET, Yang R, Robertson P Jr (2009) Pharmacokinetic profile of armodafinil in healthy subjects: pooled analysis of data from three randomized studies. Clin Drug Investig 29: $87-100$

24.Brazilian Sanitary Surveillance Agency Guideline (2002) Manual of Good Bioavailability and Bioequivalence Practices.

25.Guidance for Industry Bioavailability and Bioequivalence Studies for Orally Administered Drug Products-General Considerations, US Dept of Health and Human Services, Food and Drug Evaluation and Research (CDER). (March 2003).

26.USFDA, Guidance for Industry, Bioanalytical Method Valdiation (May 2001).

27.SAS Institute Inc, SAS/STAT User's guide, Version 6, (4thedn), Vol. 2 , SAS Institute, Cary, NC, 1990.

28.Westlake WJ (1972) Use of confidence intervals in analysis of comparative bioavailability trials. J Pharm Sci 61: 1340-1341.

29.Mandallaz D, Mau J (1981) Comparison of different methods for decision-making in bioequivalence assessment. Biometrics 37: 213222.

30.Locke CS (1984) An exact confidence interval from untransformed data for the ratio of two formulation means. J Pharmacokinet Biopharm 12: 649-655. 